\title{
VENTILATOR ASSOCIATED PNEUMONIA IN TRAUMA PATIENTS; ASSOCIATED RISK FACTORS, MICROBIAL ETIOLOGY AND OUTCOME
}

\author{
Sohaima Manzoor, Farzana Batool, Muneeba Ahsan Sayeed, Azizullah Khan Dhiloo*, Humera Muhammad Ismail, Shehla Baqi \\ Shaheed Mohtarma Benazir Bhutto Institute of Trauma \& Civil Hospital, Karachi Pakistan, *Dow University of Health Sciences, Karachi Pakistan
}

ABSTRACT

Objective: To study the occurrence, risk factors and outcome of Ventilator Associated Pneumonia (VAP) in trauma patients. Study Design: Prospective observational study.

Place and Duration of Study: Shaheed Mohtarma Benazir Bhutto Institute of Trauma, Karachi Pakistan, from Jul to Dec 2019. Methodology: All trauma patients, above 12 years, placed on mechanical ventilation in the ER or ICU, were enrolled. Patients that developed a Clinical Pulmonary Infection Score of $>6$ were diagnosed with Ventilator Associated Pneumonia.

Results: A total of 113 patients were enrolled. Mean age was $32.9 \pm 14.4$ years; 105 (92.9\%) were males. Thirty-eight (33.6\%) patients developed VAP. Patients with VAP, compared to non-VAP, had a longer Emergency Room (ER) stay of $7.8 \pm 10.1$ vs $4.7 \pm 7.4$ days ( $p$-value 0.013 ), greater ventilator days of $18.5 \pm 12.6$ vs $7.9 \pm 5.5$ ( $p$-value 0.001 ), longer hospital stay of $>14$ days in $65.8 \%$ vs $33.3 \%$ ( $p$-value 0.001 ) and higher mortality of $65.8 \%$ vs $56.0 \%$ ( $p$-value 0.213 ). Nurse to patient ratio and infection control measures for prevention of VAP were significantly reduced in Emergency Room compared to Intensive Care Unit ( $p$ value 0.001$)$. Of 43 respiratory isolates in $38 \mathrm{VAP}$ patients, 40 (93\%) were gram negatives of which 23 (57.5\%) were multidrug resistant with polymyxins as the only therapeutic option.

Conclusion: There is a high burden of VAP in patients with trauma. Prolonged retention in the ER is a significant risk factor for VAP, due to understaffing and poor infection control in the emergency setting. Policies must be instituted to improve infection control and minimize ER stay of patients.

Keywords: Emergency room (ER), Intensive care unit (ICU), Risk factors, Trauma, Ventilator associated pneumonia (VAP).

\footnotetext{
This is an Open Access article distributed under the terms of the Creative Commons Attribution License (https://creativecommons.org/licenses/by-nc/4.0/), which permits unrestricted use, distribution, and reproduction in any medium, provided the original work is properly cited.
}

\section{INTRODUCTION}

Ventilator associated pneumonia (VAP) is defined as pneumonia occurring after 48 hours of mechanical ventilation. VAP has an estimated incidence of $9-27 \%$ worldwide, and leads to prolonged ventilator support and ICU stay, financial burden and mortality. 1,2 Trauma patients have an increased incidence of VAP compared to non-trauma cases due to risk factors such as intubation in emergency settings, head and spinal injuries, chest trauma, polytrauma, surgical interventions and prior use of antibiotics. ${ }^{3-5}$

Furthermore, morbidity and mortality of patients with VAP is increasing due to multi drug resistant (MDR) organisms.6,7 Knowledge of antimicrobial susceptibility is essential for effective management of patients with VAP. Most importantly, infection control measures must be followed for the prevention of VAP and spread of MDR organisms.

There is limited data in Pakistan of VAP in trauma patients. These have significant additional risk factors as compared with non-trauma patients, requiring further study. Our objective was to study risk factors and patient outcome in trauma patients who

Correspondence: Dr Sohaima Manzoor, Shaheed Mohtarma Benazir Bhutto Institute of Trauma \& Civil Hospital, Karachi Pakistan Received: 11 Feb 2021; revised received: 10 Mar 2021; accepted: 10 Mar 2021 develop VAP and to identify the causative microorganisms of VAP. This will assist in identifying the burden of VAP and provide guidance regarding the most appropriate empirical coverage for its treatment and prevention of VAP in our institute.

\section{METHODOLOGY}

An observational prospective study was conducted at Shaheed Mohtarma Benazir Bhutto Institute of Trauma (SMBBIT), Karachi Pakistan. This is a government health care facility located in Karachi, a city with an estimated population of 30 million. The trauma center serves this population and rest of Sindh and neighboring Balochistan.

We planned for a minimum study duration of 6 months. The study was conducted from July 2019 to December 2019. Based on the previous estimate of VAP in $45 \%$ of patients, with a margin of error of $10 \%$ and $95 \%$ confidence interval, sample size of 96 patients were included in our study, with an additional 17 patients recruited by the completion of the 6 month study period, coming to a total of 113 patients, using the Open-Epi online sample size calculator. ${ }^{5}$ All mechanically ventilated patients admitted to the ER and ICU were identified each morning with the intent to enroll patients within 48 hours of their intubation. Only those with traumatic injury, $\geq 12$ years of age, and who had 
been placed on mechanical ventilation at SMBBIT were included. Those patients with pneumonia prior to or in less than 48 hours of intubation, as evident on imaging were excluded.

Patient data was collected and filled in the designed proforma which included demographics, diagnosis, location in ER or ICU at enrollment, mechanism of injury, type of trauma, date of mechanical ventilation and onset of VAP and whether it occurred in ER or ICU, timing of VAP in terms of early or late, radiological presentation, microbiological etiology and management of VAP patients and overall outcome. The Medical Information System was accessed for radiological, laboratory and microbiological data.

For purposes of determining the Clinical Pulmonary Infection Score (CPIS) ${ }^{8}$, we noted the temperature, white blood cell count, presence or absence and nature of tracheal secretions, oxygenation $(\mathrm{PaO} 2 / \mathrm{FiO} 2)$, chest radiographs and tracheal aspirate cultures. ${ }^{8}$ Those patients with a CPIS of $>6$ were given a diagnosis of VAP, endotracheal and blood cultures sent and antibiotics initiated empirically.

At the point of enrollment, the primary nursing staff assigned to the patient was evaluated by observation and enquiry for adherence to recommended preventive measures for VAP. Guidelines recommend elevation of head of bed between $30^{\circ}$ and $45^{\circ}$, daily assessment for readiness for extubation, regular mouth care ${ }^{9}$ and peptic ulcer disease prophylaxis. General observations in the ER or ICU were also made at patient enrollment and included nurse to patient ratio, a ratio of 1:2 being considered optimal for ventilated patients, and availability of alcohol based hand rubs at point of patient care.10-12 On quiet observation of a healthcare worker in the patient area whether ER or ICU, adherence to hand hygiene was assessed.

Primary outcome was occurrence of VAP. Patients were followed for the duration of intubation, and for 48 hours post-extubation. Final disposition of patients surviving beyond this period was abstracted from the Health Information Medical Systems.

Approval for the study was obtained by institutional ethical review committee (ERC\# 00001SMBBIT). VAP was clinically diagnosed by using Clinical Pulmonary Infection Score (CPIS). ${ }^{8}$ A score of $>6$ was consistent with VAP. Multi Drug Resistant organism (MDR) was defined as resistance in gram negative organisms to antibiotics in $\geq 3$ classes of antibiotics. ${ }^{13}$
Extended Spectrum Beta Lactamases (ESBL) was defined as gram negative bacteria resistant to $1^{\text {st }}, 2^{\text {nd }}$ and $3^{\text {rd }}$ generation cephalosporins and monobactams. ${ }^{14}$ MRSA was defined as staphylococcus aureus resistant to methicillin. Early onset VAP was defined as VAP occurring in 4 or lesser days of intubation. ${ }^{15}$ Late onset VAP was defined as VAP occurring more than 4 days after intubation.

Data was entered and analyzed on Statistical Package for Social Sciences (SPSS) version 24. Continuous variables were summarized as mean and standard deviation for age, GCS, ventilator days, ER stay in days and days of hospitalization and their mean differences were evaluated using student two sample " $t$ " test. Frequency and percentages were reported for qualitative variables like age groups, gender mechanism of injuries etc. Fisher's exact test and Chi-square test was applied when two or more set of variables were compared, with pvalue of $\leq 0.05$ considered as statistically significant.

\section{RESULTS}

A total of 113 patients were enrolled. Mean age was $32.9 \pm 14.4$ years; 105 (92.9\%) were males and 8 $(7.1 \%)$ were females. Of 113 , almost half were residents of Karachi. The commonest cause of trauma was road traffic accidents in $88(77.8 \%)$. Polytrauma was found in $35(31 \%)$ (Table-I).

Out of 113 mechanically ventilated trauma patients, $38(33.6 \%)$ developed VAP. Of these 21 $(55.3 \%)$ were admitted in ICU and $17(44.7 \%)$ in ER at the time of VAP diagnosis. Of 38,31 patients $(81.6 \%)$ had late onset VAP developing more than 4 days after intubation.

We compared patients with and without VAP for age, gender, Glasgow Coma Scale (GCS), location in hospital where intubated, mechanism of injury, head and chest injuries and surgical procedures and none were found to be significant risk factors for the development of VAP (Table-II).

Duration of ER stay after mechanical ventilation was documented in all study patients and the average duration was 5.8 days. Of 113, $52(46.0 \%)$ were retained in the ER for their entire duration of mechanical ventilation prior to transfer to ICU, ward, discharge or death. Patients who developed VAP were found to have a longer duration of stay in the ER of 7.8 \pm 10.1 days as compared to $4.7 \pm 7.4$ days in those that did not develop VAP, which was found to be significant $(p-$ value 0.013 ). VAP patients, compared to non-VAP, had 
Table-I: Demographics and baseline characteristics of mechanically ventilated patients with trauma $(n=113)$.

\begin{tabular}{|c|c|}
\hline Variables & n (\%) \\
\hline Age in years* & $32.9 \pm 14.4$ \\
\hline \multicolumn{2}{|l|}{ Gender } \\
\hline Male & $105(92.9)$ \\
\hline Female & $8(7.1)$ \\
\hline \multicolumn{2}{|l|}{ Residential Area } \\
\hline Karachi & $54(47.8)$ \\
\hline Sindh (outside Karachi) & $47(41.6)$ \\
\hline Balochistan & $12(10.6)$ \\
\hline \multicolumn{2}{|l|}{ Location at Enrollment } \\
\hline Emergency Room & $57(50.4)$ \\
\hline Intensive Care Unit & $56(49.6)$ \\
\hline \multicolumn{2}{|l|}{ Mechanism of Injuries } \\
\hline Road Traffic Accident & $88(77.9)$ \\
\hline Fall & $6(5.3)$ \\
\hline Gun shot & $5(4.4)$ \\
\hline Assault & $6(5.3)$ \\
\hline Electrocution & $3(2.7)$ \\
\hline Self-harm & $3(2.7)$ \\
\hline Others & $4(3.5)$ \\
\hline \multicolumn{2}{|l|}{ Injuries } \\
\hline Head & $86(76.1)$ \\
\hline Chest & $28(24.8)$ \\
\hline Poly Trauma & $35(31)$ \\
\hline Glasgow Coma Scale at Admission* & $10.1 \pm 3.8$ \\
\hline \multicolumn{2}{|l|}{ Location of Intubation } \\
\hline Intensive Care Unit & $10(8.8)$ \\
\hline Emergency Room & $67(59.3)$ \\
\hline Operation Room & $35(31)$ \\
\hline Ward & $1(0.9)$ \\
\hline Ventilator Associated Pneumonia & $38(33.6)$ \\
\hline Days of Stay in Emergency Room* & $5.8 \pm 8.5$ \\
\hline Ventilator Days* & $11.3 \pm 9.9$ \\
\hline Duration of hospitalization* & $18.3 \pm 15.8$ \\
\hline Duration of hospitalization (>14 days) & $50(44.2)$ \\
\hline \multicolumn{2}{|l|}{ Outcome } \\
\hline Discharge & $31(27.4)$ \\
\hline Transfer & $12(10.6)$ \\
\hline Left Against Medical Advice & $1(0.9)$ \\
\hline Lost to Follow-up & $2(1.8)$ \\
\hline Death & $67(59.3)$ \\
\hline
\end{tabular}

a higher number of ventilator days, $18.5 \pm 12.6$ vs 7.9 \pm 5.5 ( $p$-value 0.001$)$, longer hospital stay of $>4$ days, $65.8 \%$ vs $33.3 \%$ ( $p$-value 0.001$)$, and higher mortality of $65.8 \%$ vs $56.0 \%$ ( $p$-value 0.213 ) (Table-II).

Nurse to patient ratio in ER was not optimal at 1:2 for ventilated patients but was adequate in ICU. Availability of alcohol based hand rub at point of patient care was lacking in ER whereas in ICU, ABHRs were readily available.

Implementation of recommended infection control practices of hand hygiene, elevation of head of bed
Table-II: Associated risk factors for ventilator associated pneumonia (VAP) and outcome in trauma patients.

\begin{tabular}{|c|c|c|c|}
\hline Variables & $\begin{array}{c}\text { Non-VAP } \\
\mathrm{n}=75, \mathrm{n}(\%)\end{array}$ & $\begin{array}{c}\text { VAP } \\
n=38, n(\%)\end{array}$ & $\begin{array}{c}p- \\
\text { value }\end{array}$ \\
\hline Age in years* & $33.8 \pm 14.8$ & $31.3 \pm 13.6$ & 0.234 \\
\hline$\leq 35$ years & $45(60)$ & $29(76.3)$ & \multirow{2}{*}{0.063} \\
\hline$>35$ years & $30(40)$ & $9(23.7)$ & \\
\hline \multicolumn{4}{|l|}{ Gender } \\
\hline Male & $70(93.3)$ & $35(92.1)$ & \multirow{2}{*}{0.543} \\
\hline Female & $5(6.7)$ & $3(7.9)$ & \\
\hline $\begin{array}{l}\text { Glasgow Coma Scale on } \\
\text { admission* }\end{array}$ & $10.4 \pm 3.8$ & $9.6 \pm 3.9$ & 0.739 \\
\hline \multicolumn{4}{|l|}{ Mechanism of Injury } \\
\hline Road Traffic Accident & $57(76)$ & $31(81.6)$ & \multirow{2}{*}{0.337} \\
\hline Other than RTA & $18(24)$ & $7(18.4)$ & \\
\hline Poly Trauma & $25(33.3)$ & $10(26.3)$ & 0.295 \\
\hline \multicolumn{4}{|l|}{ Injuries / Procedures } \\
\hline Head injuries & $56(74.7)$ & $30(78.9)$ & 0.398 \\
\hline Chest injuries & $20(26.7)$ & $8(21.1)$ & 0.341 \\
\hline Chest tube & $18(66.7)$ & $9(33.3)$ & 0.583 \\
\hline Surgical Procedures & $49(65.3)$ & $26(68.4)$ & 0.456 \\
\hline Tracheostomy & $19(25.3)$ & $26(68.4)$ & $<0.001$ \\
\hline \multicolumn{4}{|l|}{ Location of Intubation } \\
\hline Intensive Care Unit & $7(9.3)$ & $3(7.9)$ & \multirow{4}{*}{0.331} \\
\hline Emergency Room (ER) & $42(56)$ & $25(65.8)$ & \\
\hline Operation Room & $26(34.7)$ & $9(23.7)$ & \\
\hline Ward & - & $1(2.6)$ & \\
\hline $\begin{array}{l}\text { Days of Stay in } \\
\text { Emergency Room }\end{array}$ & $4.7 \pm 7.4$ & $7.8 \pm 10.1$ & 0.013 \\
\hline Ventilator Days* & $7.9 \pm 5.5$ & $18.5 \pm 12.6$ & $<0.001$ \\
\hline Days of hospitalization* & $15.9 \pm 15.8$ & $23 \pm 14.8$ & 0.785 \\
\hline $\begin{array}{l}\text { Duration of hospita- } \\
\text { lization ( }>14 \text { days) }\end{array}$ & $25(33.3)$ & $25(65.8)$ & 0.001 \\
\hline Mortality & $42(56.0)$ & $25(65.8)$ & 0.213 \\
\hline
\end{tabular}

at $30-45^{\circ}$, daily assessment for readiness for extubation and regular mouth care was found to be significantly reduced in ER as compared to ICU ( $p$-value 0.001) (Table-III).

Table-III: Infection control measures for the prevention of VAP documented at enrollment of study patients $(n=113)$.

\begin{tabular}{|c|c|c|c|}
\hline Variables & $\begin{array}{c}\text { ICU } \\
n=56,(\%)\end{array}$ & $\begin{array}{c}\mathrm{ER} \\
\mathrm{n}=57,(\%)\end{array}$ & $\begin{array}{c}p- \\
\text { value }\end{array}$ \\
\hline Hand Hygiene & $42(75.0)$ & $8(14.0)$ & $<0.001$ \\
\hline $\begin{array}{l}\text { Elevation of head at } 30^{\circ} \\
\text { to } 45^{\circ}\end{array}$ & $54(92.9)$ & 27 (47.4) & $<0.001$ \\
\hline $\begin{array}{l}\text { Daily assessment for } \\
\text { extubation }\end{array}$ & $50(89.3)$ & $21(36.8)$ & $<0.001$ \\
\hline $\begin{array}{l}\text { Frequency of mouth } \\
\text { care per } 24 \text { hours }\end{array}$ & $3.1 \pm 0.6$ & $1.4 \pm 0.8$ & $<0.001$ \\
\hline $\begin{array}{l}\text { Peptic ulcer disease } \\
\text { prophylaxis }\end{array}$ & $56(100)$ & $57(100)$ & \\
\hline
\end{tabular}

Endotracheal cultures from VAP patients were mono-microbial in $21(55.3 \%)$, polymicrobial in 11 
(28.9\%) whereas 6 (15.8\%) yielded no growth (Figure). A total of 43 isolates were obtained from endotracheal cultures of 38 VAP patients. Of 43 isolates, Klebsiella spp. Was most frequently recovered in 17 (39.5\%), followed by Acinetobacter spp. in 10 (23.3\%). Overall, of 43 isolates, $40(93 \%)$ were gram negatives of which 23 (57.5\%) were MDRO and $14(35 \%)$ were ESBL producing organisms (Figure). Of $38 \mathrm{VAP}$ patients, 10 (26.3\%) were bacteremic with gram negatives isolated in 9 $(90 \%)$ with no correlation seen between endotracheal and blood culture isolates.

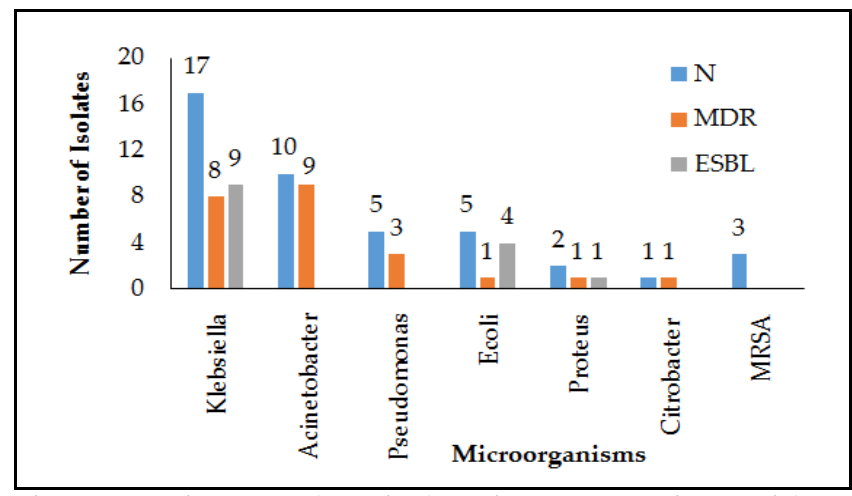

Figure: Respiratory culture isolates in trauma patients with ventilator associated pneumonia $(n=43)$.

\section{DISCUSSION}

In our study, VAP occurred in 33\% of mechanically ventilated trauma patients, whereas in Pakistan, in non-trauma patients incidence of VAP of 30.5-66.8\% has been reported. ${ }^{16,17}$ There is scarce data of VAP in trauma patients in Pakistan with which to compare our findings. Data from the National Healthcare Safety Networkin the United States reported 4 times higher incidence of VAP in trauma compared to non-trauma patients. ${ }^{18}$ Armugan et al, reported a VAP rate of $17.2 \%$ in trauma patients at a hospital in Qatar. ${ }^{1}$ AJ. Mangram et al, reported VAP in $9.1 \%$ of trauma patients in Arizona, USA. ${ }^{4}$ The higher rate found in trauma patients has been attributed to increased head and neck injuries, chest trauma, and low GCS with increased probability of aspiration. However, these factors were not found to be significant in our study. Increasing age, considered a risk factor for VAP, was also not significant in our study patients, two thirds of whom were $<35$ years old. 4,19

Most of our patients developed late onset VAP with higher number of ventilator days found to be a significant risk factor for VAP. Trauma, especially brain and chest injuries require early intubation and may need prolonged mechanical ventilation. VAP in itself leads to increased duration of mechanical ventilation and hospitalization. 19,20,21

The ER at the Trauma Institute retains ventilated patients till such time that they can be shifted to the ICU. Due to shortage of ICU beds, ventilated patients had a prolonged stay in the ER, averaging several days. We found that prolonged retention in the ER was a significant risk factor for the development of VAP. A study conducted in USA of mechanically ventilated trauma patients also reported increased risk of pneumonia by $20 \%$ with every hour increase in ER stay, the longest retention in ER being 281.3 minutes. ${ }^{22,23}$

We demonstrated that, as compared with the ICU, the Emergency Room nurse to patient ratio was not optimal for mechanically ventilated patients. Although 1:4 ratio is acceptable for the Emergency Room, in case of mechanically ventilated patients a ratio of no more than 1:2 is suggested. ${ }^{10,11}$

We noted a low adherence to correct infection control practices for the prevention of VAP in the ER as compared with the ICU, likely a reflection of the shortage of staff. ${ }^{10}$ Hand hygiene is an essential measure in the prevention of VAP. However, alcohol based hand rubs (ABHRs) were not available at point of patient care in the ER.

Our data underscores the need to establish systems that minimize the retention time in the ER of patients, with timely shifting of ventilated patients to the ICU. Given that our hospital is the leading Trauma center in the city, we must expand the number of ICU beds. Concurrently, ER must be strengthened in terms of staffing. That in itself may lead to better compliance with good infection control practices.

Our study found higher mortality in trauma patients with VAP as compared to non VAP patients (65.8\% vs $56 \%$ ), though not statistically significant. A study conducted in Thailand reported a lower mortality of $41.3 \%$ in trauma patients compared to $58.7 \%$ in non-trauma patients. ${ }^{24}$ Similarly, Chaari A et al, found not much difference in mortality in trauma patients with VAP when compared to non-VAP in a retrospective study in Tunisia. ${ }^{21}$

Most respiratory isolates in our trauma patients with VAP were gram negative organisms with Klebsiella being the commonest, followed by Acinetobacter, with the majority multidrug resistant, sensitive to Polymyxins alone. This is similar to other studies done in Asia and Middle Eastern countries. In India, Saravu et al, reported Klebsiella, Acinetobacter and 
Pseudomonas as major pathogens in VAP with MDR rates of $40 \%$ and Mathai et al, also reported gram negatives in $87 \%$ of respiratory isolates in VAP patients. ${ }^{20,25}$ High levels of antimicrobial resistance further emphasizes the need for strict adherence to infection control measures.

Our study was prospective and therefore was able to evaluate infection control aspects, which is essential in any study of VAP. Limitations were that we were unable to compare with non-trauma patients, since we are primarily a trauma institute.

\section{Disclaimer}

Abstract presented as poster in Medical Microbiology and Infectious Diseases Society of Pakistan conference held in February 2020 in Lahore, Pakistan.

\section{CONCLUSION}

There is a high burden of Ventilator associated Pneumonia in patients with trauma. Prolonged retention in the $\mathrm{ER}$ is a risk factor for the development of VAP, which may be related to inadequate nurse to patient ratio and low adherence to measures for the prevention of VAP in the emergency setting. Policies must be instituted that limit ER stay to within hours, not days. More ICU beds must be made available to meet the needs of a trauma institute in the most populous city of Pakistan. Implementation of good infection control practices is essential for prevention of VAP and spread of Antimicrobial Resistance. Use of polymyxinempirically for VAP is appropriate in institutions with a high incidence of Multi Drug Resistant gram negative infections.

\section{Conflict of Interest: None. \\ REFERENCES}

1. Arumugam SK, Mudali I, Strandvik G, El-Menyar A, Al-Hassani A. Risk factors for ventilator-associated pneumonia in trauma patients: A descriptive analysis. World J Emerg Med 2018; 9(3): 203.

2. Deshmukh B, Kadam S, Thirumugam M, Rajesh K. Clinical study of ventilator-associated pneumonia in tertiary care hospital, Kolhapur, Maharashtra, India. Int J Res Med Sci 2017; 5(5): 2207.

3. Cook A, Norwood S, Berne J. Ventilator-associated pneumonia is more common and of less consequence in trauma patients compared with other critically ill patients. J Trauma Acute Care Surg 2010; 69(5): 1083-1091.

4. Mangram AJ, Sohn J, Zhou N, Hollingworth AK, Ali-Osman FR, Sucher JF, et al. Trauma-associated pneumonia: time to redefine ventilator-associated pneumonia in trauma patients. Am J Surg 2015; 210(6): 1056-1062.

5. Bor C, Demirag K, Okcu O, Cankayali I, Uyar M. Ventilator-associated pneumonia in critically ill patients with intensive anti-biotic usage. Pak J Med Sci 2015; 31(6): 1441.

6. Malik MI, Malik M, Chaudhary A. Antimicrobial susceptibility pattern of bacteria isolated from tracheal secretions in intensive care units admitted patients of Lahore General Hospital. PakJ Chest Med 2018; 24(2): 72-77.

7. Ghotaslou R, Sadeghi MR, Akhi MT, Hasani A, Asgharzadeh M. Prevalence and antimicrobial susceptibility patterns of ESBL, ampC and carbapenemase-producing enterobactericeae isolated from hospitalized patients in Azerbaijan, Iran J Pharm Res 2018; 17(Suppl-1): 79.
8. Fartoukh M, Maître B, Honoré S, Cerf C, Zahar JR, Brun-Buisson C. Diagnosing pneumonia during mechanical ventilation: the clinical pulmonary infection score revisited. Am J Respir Crit Care Med 2003; 168(2): 173-179.

9. Hua F, Xie H, Worthington HV, Furness S, Zhang Q, Li C. Oral hygiene care for critically ill patients to prevent ventilator-associated pneumonia. Cochrane Datab Syst Rev 2016; 10(10): CD008367.

10. Hugonnet S, Uçkay I, Pittet D. Staffing level: a determinant of lateonset ventilator-associated pneumonia. Crit Care 2007; 11(4): R80.

11. Education LN. The importance of the optimal nurse-to-patient ratio. Lippincott Nursing Last accessed 2016; 28(1): 2020.

12. World Health Organization. WHO guidelines on hand hygiene in health care: first global patient safety challenge clean care is safer care. World Health Organization; 2009. [Internet] Available from: https://www.who.int/gpsc/5may/tools/who_guidelineshandhygiene_summary.pdf (Accessed on: 6th March 2021,

13. Salehi M, Jafari S, Ghafouri L, Ardakani HM, Abdollahi A, Beigmohammadi MT, et al. Ventilator-associated Pneumonia: Multidrug Resistant Acinetobacter vs. Extended Spectrum Beta Lactamaseproducing Klebsiella. J Infect Dev Ctries 2020; 14(6): 660-663.

14. Teklu DS, Negeri AA, Legese MH, Bedada TL, Woldemariam HK, Tullu KD. Extended-spectrum beta-lactamase production and multidrug resistance among Enterobacteriaceae isolated in Addis Ababa, Ethiopia. Antimicrob Resist Infect Control 2019; 8(1): 39-42.

15. Restrepo MI, Peterson J, Fernandez JF, Qin Z, Fisher AC, Nichol-son SC. Comparison of the bacterial etiology of early-onset and late-onset ventilator-associated pneumonia in subjects enrolled in 2 large clinical studies. Respir Care 2013; 58(7): 1220-1225.

16. Kumar A, Ghauri MI, Razzaque S, Jamali A, Mohammad JS. Ventilator associated pneumonia; prevalence and microbial patterns. PakJ Chest Med 2015; 20(2): 1-5.

17. Ijaz T, Aslam S, Raja S, Ahmad B, Anjum A, Ijaz S. A study of antibiogram assay, risk factors and etiology of ventilator associated pneumonia (VAP) in a tertiary care hospital of Pakistan. Eur Respir J 2013; 42(Suppl-57): p2745.

18. Dudeck MA, Weiner LM, Allen-Bridson K, Malpiedi PJ, Peterson KD, Pollock DA, et al. National Healthcare Safety Network (NHSN) report, data summary for 2012, device-associated mo-dule. Am J Infect Control 2013; 41(12): 1148-1166.

19. Younan D, Delozier SJ, Adamski J, Loudon A, Violette A, Ustin J, et al. Factors Predictive of ventilator-associated pneumonia in critically Ill trauma patients. World J Surg 2020; 44(4): 1121-1125.

20. Mathai AS, Phillips A, Kaur P, Isaac R. Incidence and attributable costs of ventilator-associated pneumonia (VAP) in a tertiary-level intensive care unit (ICU) in northern India. J Infect Public Health 2015; 8(2): 127-135.

21. Chaari A, Kssibi H, Zribi W, Medhioub F, Chelly H, Algia NB, et al. Ventilator-associated pneumonia in trauma patients with open tracheotomy: Predictive factors and prognosis impact. J Emerg Trauma Shock 2013; 6(4): 246.

22. Carr BG, Kaye AJ, Wiebe DJ, Gracias VH, Schwab CW, Reilly PM. Emergency department length of stay: a major risk factor for pneumonia in intubated blunt trauma patients. J Trauma Acute Care Surg 2007; 63(1): 9-12.

23. Cline SD, Schertz RA, Feucht EC. Expedited admission of patients decreases duration of mechanical ventilation and shor-tens ICU stay. Am J Emerg Med 2009; 27(7): 843-846.

24. Chittawatanarat K, Jaipakdee W, Chotirosniramit N, Chandac-ham $\mathrm{K}$, Jirapongcharoenlap T. Microbiology, resistance patterns, and risk factors of mortality in ventilator-associated bacterial pneumonia in a Northern Thai tertiary-care university based general surgical intensive care unit. Infect Drug Resist 2014; 7(1): 203-210.

25. Saravu K, Preethi V, Kumar R, Guddattu V, Shastry AB, Mukhopadhyay $C$. Determinants of ventilator associated pneumonia and its impact on prognosis: a tertiary care experience. Indian journal of critical care medicine: peer-reviewed, Ind J Crit Care Med 2013; 17(6): 337-342. 